Cite this: RSC Advances, 2013, 3, 10197

\title{
Green and one-step synthesis of gold nanoparticles incorporated into electrospun cyclodextrin nanofibers $\dagger$
}

Received 11th March 2013,

Asli Celebioglu and Tamer Uyar*

Accepted 9th May 2013

DOI: $10.1039 / c 3 r a 41175 c$

www.rsc.org/advances

The green and one-step synthesis of gold nanoparticles (Au-NP) incorporated into electrospun cyclodextrin-nanofibers (CD-NF) without the use of a carrier polymer matrix was achieved in this study. Chemically modified CD (hydroxypropyl- $\beta$-cyclodextrin $(H P \beta C D)$ ) was used as both a reducing and stabilizing agent as well as a fiber matrix for the electrospinning of HPBCD/Au-NP-NF composite mats. Electrospinning of metallic NP incorporating CDNF would have exclusive properties by combining the very large surface area of nanofibers with specific functionality of the metal NP and CD.

Metal nanoparticles (NP) especially gold (Au) have received great attention due to their unique optical, chemical and electronic properties along with their wide range of promising applications in photonics, biomedicine, catalysis, sensing and nanoelectronics, etc. ${ }^{1}$ A variety of approaches can be used for the synthesis of Au-NP and the most common one is the wet chemical method by using an appropriate reducing agent and stabilizer or templates in order to obtain NP from their salt precursors. ${ }^{2}$ The wet chemical methods for the synthesis of Au-NP are sometimes quite complex, time-consuming, or require strict synthetic conditions and the use of hazardous reducing and stabilizing chemicals, therefore, simple and versatile approaches for the synthesis of size and shape controlled uniform NP are always desired for practical applications. So, recent studies are more focused on developing environmentally friendly and economically viable methods for the synthesis of NP as well as other nanomaterials. For instance, some biomolecules have been used as environmentally friendly socalled "green" reducing and capping agents for the synthesis of Au-NP. As an alternative to toxic reducing and stabilizing agents, "green" approach was reported by using naturally-occurring macromolecules such as chitosan ${ }^{3}$ and cellulose ${ }^{4}$ or natural water-soluble polyphenols ${ }^{5}$ which can be utilized as both reducing agent and stabilizing agents for the synthesis of Au-NP. On the other hand, cyclodextrins (CD) are naturally occurring nontoxic

UNAM-Institute of Materials Science \& Nanotechnology, Bilkent University, Ankara, 06800, Turkey. E-mail: tamer@unam.bilkent.edu.tr

$\dagger$ Electronic supplementary information (ESI) available: experimental details and further characterization of materials. See DOI: 10.1039/c3ra41175c water-soluble cyclic oligosaccharides which are also shown to be very effective stabilizing agent for the formation of Au-NP and their size control. ${ }^{6 a-e}$ Here, we report a green and one-step synthesis of Au-NP incorporated in electrospun CD nanofibers; CD was used as reducing and stabilizing agent as well as fiber template for the fabrication of $\mathrm{CD}$ nanofiber composites incorporating Au-NP via electrospinning technique.

CD are produced from starch by means of enzymatic conversion and they have truncated cone-shaped molecular structure. The three native $\mathrm{CD}$ are named as $\alpha-\mathrm{CD}, \beta-\mathrm{CD}$ and $\gamma$-CD having six, seven or eight glucopyranose units in the cyclic, respectively. In addition, the chemically modified $\mathrm{CD}$ can be produced by substitution of the hydroxyl groups of $\mathrm{CD}$ with methyl, hydroxypropyl or some other groups. ${ }^{7} \mathrm{CD}$ can form fascinating supramolecular structures by forming non-covalent host-guest inclusion complexes with variety of molecules and therefore $\mathrm{CD}$ are quite applicable in pharmaceuticals, food, chromatography, cosmetics and textiles, etc. ${ }^{8}$ In the recent years, the use of $\mathrm{CD}$ as the stabilizer and/or reducing agent for the synthesis of metal-NP such as gold, ${ }^{6 a-e}$ silver, $^{6 e, f}$ palladium $^{9}$ and platinum $^{10}$ have also been reported.

Over the past decade, electrospinning has become the most practical technique for the production of nanofiber and nanofibrous mats in the form of non-woven. Electrospun nanofibers and their mats have unique properties including very high specific surface area, nanoscale porous structures, and distinct physical and mechanical properties along with design flexibility for physical and chemical functionalization. The electrospun nanofibers/nanofibrous mats are particularly applicable for filtration, tissue engineering, drug delivery, energy, sensor, electronics and environment, etc. ${ }^{11}$ Electrospinning of functional nanofibers can be performed from variety of materials such as polymers, polymer blends, sol-gels, suspensions, emulsions, composite structures as well as supramolecular systems, etc. ${ }^{11 a, b, 12}$ In addition, it is fairly easy to improve the functionality of the electrospun nanofibers by incorporating functional additives such as NP which have various applications due to their unique sensing, optical, catalytically and antibacterial properties. ${ }^{13}$ 
Here, we report a green and one-step synthesis of Au-NP incorporated in electrospun cyclodextrin-nanofibers (CD-NF). Chemically modified CD (hydroxypropyl- $\beta$-cyclodextrin (HP $\beta C D)$ ) was used as both reducing and stabilizing agent as well as fiber matrix for the one-step electrospinning of $\mathrm{HP} \beta \mathrm{CD} / \mathrm{Au}-\mathrm{NP}-\mathrm{NF}$ composites. The synthesis of Au-NP from hydrochloroauric acid $\left(\mathrm{HAuCl}_{4}\right)$ with a small size and narrow distribution was achieved by using HP $\beta C D$ only. The electrospinning of the very same HP $\beta C D$ solution incorporating Au-NP was carried out to produce HP $\beta C D / A u-N P-N F$ composites. Two different solvent systems (DMF and water) and two different NP loadings (1 wt \% and 2 $\mathrm{wt} \%$ ) were used for the fabrication of these nanofibrous composites. It was observed that the size of the NP and their dispersion within the HP $\beta$ CD NF matrix were highly depend on the solvent type and the wt $\%$ of metal salts used.

$\mathrm{HAuCl}_{4}$ was added to highly concentrated HP $\beta C D$ solution $(160 \%(\mathrm{w} / \mathrm{v})$ in water or $120 \%(\mathrm{w} / \mathrm{v})$ in $\mathrm{DMF})$. The clear and transparent HP $\beta C D$ solution became dark purple after mixing over-night indicating the formation of Au-NP. The HP $\beta C D / A u-N P$ solutions were then electrospun into bead-free NF (Fig. 1). Although the electrospinning of fibers from non-polymeric systems is quite challenging, very recently, we have successfully electrospun uniform NF from chemically modified CD without using any carrier polymeric matrix. ${ }^{14}$ The electrospinning of highly concentrated modified CD solutions was due to the presence of considerable CD aggregates by self-assembly via intermolecular interactions. The HP $\beta C D$ concentration in water $(160 \%, w / v)$ and DMF $(120 \%$, w/v) systems were already optimized from our previous study in order to obtain bead-free NF. ${ }^{14 b}$ The detailed structural characterizations of the HP $\beta C D / A u-N P-N F$ were performed by SEM, TEM, STEM, UV-vis, XRD, XPS and FTIR.

The bead-free HP $\beta C D$ NF incorporating Au-NP were obtained from both of the solvent type (water and DMF) and different NP loading ( $1 \mathrm{wt} \%$ and $2 \mathrm{wt} \%$ ). The SEM images (Fig. 2a and S1, ESI $\dagger$ ) and the average fiber diameter (AFD) distributions of samples were given at Fig. S2, ESI $\dagger$. The HPßCD NF electrospun from DMF solution have AFD of $135 \pm 70 \mathrm{~nm}$ and $180 \pm 60 \mathrm{~nm}$ for $1 \mathrm{wt} \%$ and $2 \mathrm{wt} \%$ Au-NP, respectively. On the other hand, the AFD of
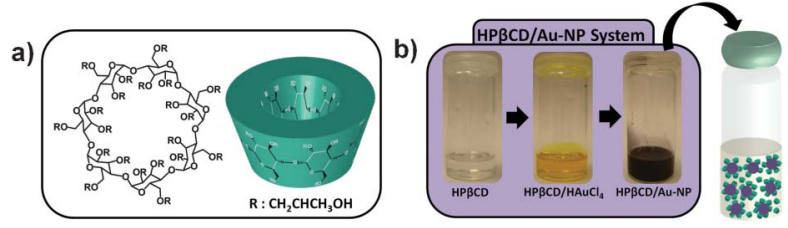

c)
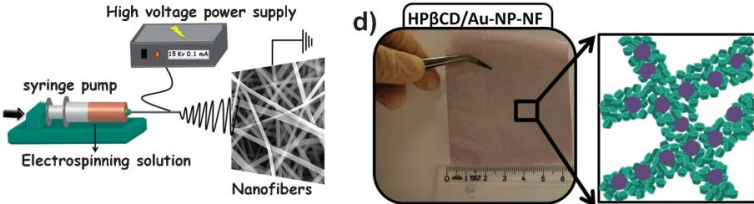

Fig. 1 (a) The Schematic representation of HP $\beta C D$ molecule. (b) As a result of the formation of NP in the solution, the color of the electrospinning solution changes from transparent to dark purple (HPBCD/Au-NP). (c) The schematic representation of electrospinning. (d) The photographs of the electrospun nanofibrous mats having the characteristic color of Au-NP and the schematic view of the samples.
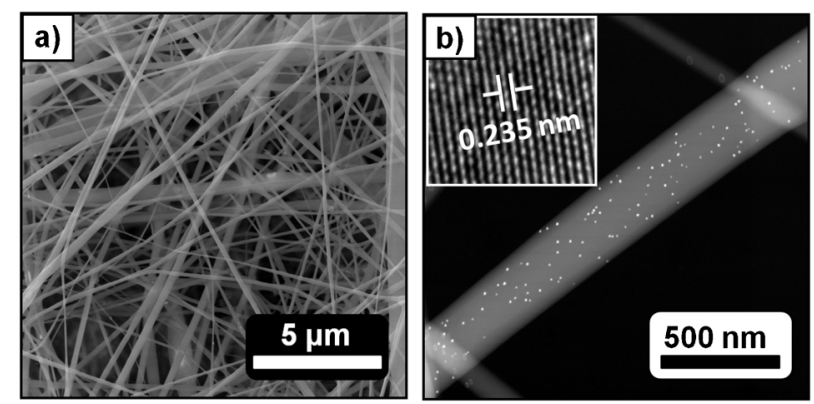

Fig. 2 (a) The representative SEM image, (b) the STEM image of the electrospun $\mathrm{HP} \beta C \mathrm{CD} / \mathrm{Au}-\mathrm{NP}-2 \%-\mathrm{NF}$ (DMF) and the HR-TEM image of a single Au-NP indicating the $d$-spacing between $A u\{111\}$ planes as inset figure.

water systems were $275 \pm 155 \mathrm{~nm}$ and $280 \pm 170 \mathrm{~nm}$ for $1 \mathrm{wt} \%$ and $2 \mathrm{wt} \%$ Au-NP, respectively (Table S1, ESI $\dagger$ ). We observed that the HP $\beta C D / A u-N P-N F$ obtained from DMF solvent system have thinner fiber diameters compared to that of water based system possibly because of the higher concentration of HP $\beta C D$ solution used for water system. In addition, increasing the weight\% of NP from $1 \%$ to $2 \mathrm{wt} \%$ resulted in slight increase in AFD. In brief, the AFD of samples were not significantly different, but slight variations were observed possibly because of some differences in solution properties such as concentration/viscosity. ${ }^{11 a}$

The representative STEM micrographs of HP $\beta \mathrm{CD} / \mathrm{Au}-\mathrm{NP}-2 \%-\mathrm{NF}$ (DMF) are shown in Fig. 2b. The TEM and STEM images and average particle size (APS) distributions (PSD) of the NP for other samples are given in Fig. S3-S5, ESI. $†$ The TEM and STEM images clearly showed that the NP have narrow size distribution and they are homogeneously dispersed in the HP $\beta C D$ NF matrix without presence of aggregation except for $\mathrm{HP} \beta \mathrm{CD} / \mathrm{Au}-\mathrm{NP}-2 \%-\mathrm{NF}$ (water) (Fig. S3 and S4, ESI + ). The APS and the PSD of the NP were calculated from the TEM images (Fig. S3, ESI $\dagger$ ) and they are varied with the wt\% loading of NP and the solvent type used. The APS of Au-NP was $8.2 \pm 1.8 \mathrm{~nm}$ and $9.1 \pm 1.4 \mathrm{~nm}$ for $\mathrm{HP} \beta \mathrm{CD} / \mathrm{Au}-\mathrm{NP}-1 \%-$ $\mathrm{NF}(\mathrm{DMF})$ and $\mathrm{HP} \beta \mathrm{CD} / \mathrm{Au}-\mathrm{NP}-2 \%-\mathrm{NF}$ (DMF), respectively. In the case of the water system, Au-NP has APS of $6.0 \pm 1.4 \mathrm{~nm}$ for HP $\beta C D / A u-N P-1 \%-N F$. However, for HP $\beta C D / A u-N P-2 \%-N F$, the size of the Au-NP got much bigger having APS of $25.1 \pm 11.0 \mathrm{~nm}$ and presence of some aggregation was obvious indicating that 2 wt \% loading is too much for attaining homogeneously distributed Au-NP in the fiber matrix from water-based system (Table S1, ESI $\dagger$ ). The NP size got bigger as the loading of Au increased from $1 \mathrm{wt} \%$ to $2 \mathrm{wt} \%$. Except for $\mathrm{HP} \beta \mathrm{CD} / \mathrm{Au}-\mathrm{NP}-2 \%-\mathrm{NF}$ (water) in which aggregation occurred, the sizes of the NP are generally smaller for water-based system compared to that of DMF system. One possibility is that water system has higher HP $\beta C D$ concentration which yielded better stabilization and resulted in smaller NP. On the other hand, we did not come across with the coagulation or local aggregation of Au-NP at higher wt\% loading (2 wt\%) for the DMF-based system probably due to the reduction ability of DMF. ${ }^{15}$

The representative HR-TEM images of Au-NP ( $2 \mathrm{wt} \% \mathrm{NP}$ ) were dispatched in Fig. 2b as inset figures. The crystalline nature of the Au-NP was confirmed by the presence of lattice fringes. From HRTEM, it was observed that the Au-NP were polycrystalline and 

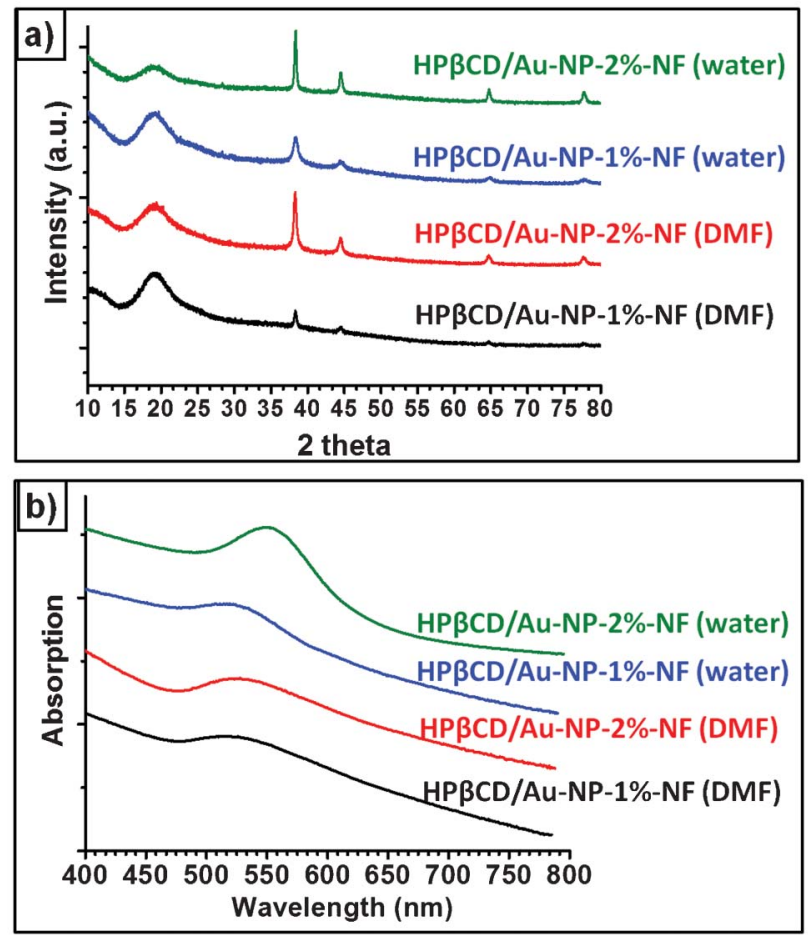

Fig. 3 (a) The XRD spectra and (b) the solid UV-vis spectra of electrospun HP $\beta C D$ / Au-NP-NF produced from two solvent systems (DMF and water) at two different NP loading (1 wt\% and $2 \mathrm{wt} \%$ )

$d$-spacing was measured to be $0.235 \mathrm{~nm}$ from the lattice fringes which corresponded to the lattice spacing of the (111) planes of the fcc Au. ${ }^{6 a}$ The crystalline nature of the Au-NP was further confirmed by XRD study. Fig. 3a shows XRD patterns of HP $\beta C D /$ Au-NP-NF and HP $\beta C D$ NF without Au-NP was also provided for the comparison (Fig. S7, ESI $)$ ). Similar to its powder form, the electrospun HP $\beta C D$ NF having an amorphous structure shows a broad halo in the XRD pattern. ${ }^{14 b}$ For HP $\beta C D / A u-N P-N F$, the broad halo having a maximum at $2 \theta \approx 18$ is due to $\mathrm{HP} \beta \mathrm{CD}$. The intense diffraction peaks at $2 \theta=38.2^{\circ}, 44.4^{\circ}, 64.6^{\circ}$, and $77.6^{\circ}$ are observed, which correspond to the (111), (200), (220), and (311) reflections of Au crystals, respectively. ${ }^{16}$ The peak intensities are higher for the $\mathrm{HP} \beta \mathrm{CD} / \mathrm{Au}-\mathrm{NP}-\mathrm{NF}$ containing $2 \mathrm{wt} \% \mathrm{Au}-\mathrm{NP}$. In addition, the intensity of $2 \theta=38.2^{\circ}$ peak is higher than the other peaks implying a certain predominance of the (111) facets in the formed Au-NP.

The solid-state UV-vis absorption spectra of the electrospun $\mathrm{HP} \beta \mathrm{CD} / \mathrm{Au}-\mathrm{NP}-\mathrm{NF}$ mats are displayed in Fig. 3b. For all HP $\beta \mathrm{CD} /$ Au-NP-NF samples, the spectra show an absorption band at the range of 520-535 $\mathrm{nm}$ due to the characteristic surface plasmonic resonance (SPR) band for Au-NP. ${ }^{17}$ The maximum absorption value for HP $\beta \mathrm{CD} / \mathrm{Au}-\mathrm{NP}-1 \%-\mathrm{NF}$ (DMF) appeared at around $525 \mathrm{~nm}$ and it slightly shifted to the $530 \mathrm{~nm}$ for the $\mathrm{HP} \beta \mathrm{CD} / \mathrm{Au}-\mathrm{NP}-2 \%-\mathrm{NF}$ (DMF) because of the increasing in the particle size (Table S1, ESI $\dagger$ ). For the HPßCD/Au-NP-1\%-NF (water), the absorption peak exhibits at around $520 \mathrm{~nm}$ with a slight blue-shift compared to DMF based system due to the smaller particle size of $1 \mathrm{wt} \%(6.0 \pm$ $1.2 \mathrm{~nm}$ ) (Table S1, ESI $\dagger$ ). ${ }^{18}$ On the other hand, the significant difference was detected between the particle size of $1 \mathrm{wt} \%$ (6.0 \pm $1.2 \mathrm{~nm})$ and $2 \mathrm{wt} \%(25.01 \pm 11.0 \mathrm{~nm})$ Au-NP loaded $\mathrm{HP} \beta \mathrm{CD} / \mathrm{Au}-$ NP-NF (water) samples, so the prominently red-shift was observed to the $545 \mathrm{~nm}$ for the HPßCD/Au-NP-2\%-NF (water) because of the some local particle aggregation.

Studies were reported regarding the formation of Au-NP by using carbohydrates (glucose, starch, etc.), ${ }^{16,18 b}$ however, these agents have limited reduction ability in the ambient conditions so $\mathrm{NaOH}$ is added to the system ${ }^{16}$ to enhance and accelerate the reduction of $\mathrm{Au}^{+3}$ to $\mathrm{Au}^{0}$. So, we have prepared alkaline condition by using $\mathrm{NaOH}(\mathrm{pH} \sim 8.5)$ to benefit from the HP $\beta \mathrm{CD}$ molecules reducing potential that have very similar chemical structure with other types of carbohydrates. At higher $\mathrm{pH}$ values, the $\mathrm{Au}-\mathrm{O}^{-}$ amount increases on the Au-NP compared to the $\mathrm{Au}-\mathrm{OH}$ groups $^{6 b, 19}$ that supplies the interaction with the $\mathrm{OH}$ groups of HP $\beta$ CD molecules. So, Au-NP are covered by the HP $\beta C D$ and their further growing and coagulations are prevented by the stabilizing effect of HP $\beta C D$ molecules. ${ }^{6 b, 20}$ Our FT-IR measurements have proved the interaction between HP $\beta C D$ molecules and NP (Fig. S8, ESI $\dagger$ ). For HP $\beta \mathrm{CD} / \mathrm{Au}-\mathrm{NP}-\mathrm{NF}$, the $-\mathrm{OH}$ stretching mode of $\mathrm{HP} \beta \mathrm{CD}$ molecules $\left(3427 \mathrm{~cm}^{-1}\right.$ ) shifted to the lower absorption band. While the HP $\beta C D / A u-N P-N F$ obtained from DMF indicated almost $17 \mathrm{~cm}^{-1}$ shift, the shift reached at about $25 \mathrm{~cm}^{-1}$ for the $\mathrm{HP} \beta \mathrm{CD} /$ Au-NP-NF produced from water system (Fig. S8, ESI†). The negative shift attributed to the prevention of the HPßCDs' molecular vibration because of the hydroxyl group interactions with $\mathrm{Au}$. Moreover, it demonstrated the reduction and stabilizing of Au-NP by the surrounding of $\mathrm{HP} \beta \mathrm{CD}$ molecules. ${ }^{6 b, 21}$ The structural characterizations of NP in HP $\beta C D$ NF matrix were also carried out by XPS study (Fig. 4). It is likely that most of the Au-NP were buried in the NF matrix, however, some Au-NP were present on the fiber surface as proven by the XPS. The XPS spectrum of the $\mathrm{HP} \beta \mathrm{CD} / \mathrm{Au}-$ NP-NF has main two doublet peaks at $88.4 \mathrm{eV}$ and $84.6 \mathrm{eV}$ belong

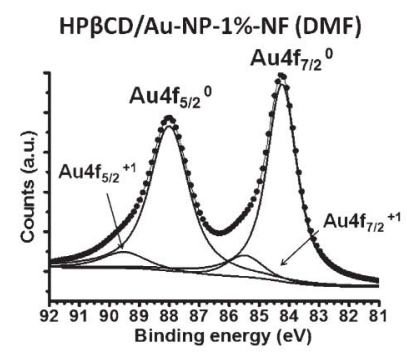

HPBCD/Au-NP-2\%-NF (DMF)
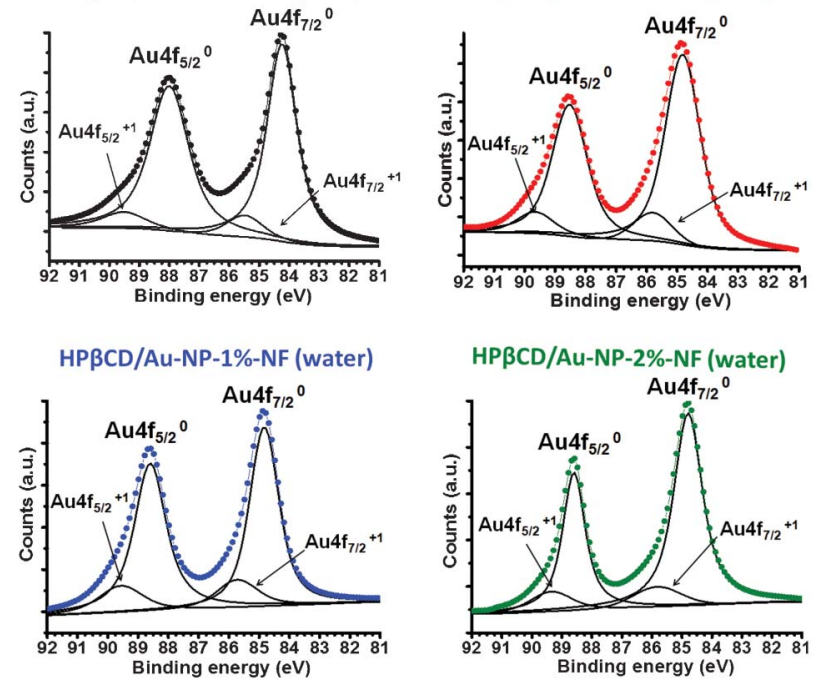

Fig. 4 The high resolution XPS of electrospun HPßCD/Au-NP-NF produced from two solvent systems (DMF and water) at two different NP loadings ( 1 wt $\%$ and 2 $w t \%)$. 
to the elemental gold $\left(\mathrm{Au}^{0}\right)$ of the binding energies of $\mathrm{Au} 4 \mathrm{f}_{5 / 2}$ and $\mathrm{Au} 4 \mathrm{f}_{7 / 2}$, respectively (Fig. 4). The second doublet observed at the $89.5 \mathrm{eV}$ and $85.6 \mathrm{eV}$ binding energies are due to $\mathrm{Au}^{+1}$ ionic type of gold. ${ }^{6 b, 22}$ While the $\mathrm{Au}^{0}$ atoms locate inner part of the Au-NP, the $\mathrm{Au}^{+1}$ ions locate outer surface to provide the interaction with the reducing agent. ${ }^{5 b, 23}$

\section{Conclusions}

In summary, HPßCD/Au-NP-NF composites were produced by electrospinning. HP $\beta C D$ was used as both reducing and stabilizing agent as well as fiber template for the green and one-step synthesis of Au-NP incorporated in electrospun HP $\beta C D-N F$. An advantage of this approach is that metallic salt was reduced and stabilized by HP $\beta C D$, a bio-derived and biocompatible non-toxic cyclic oligosaccharide, without the additional usage of toxic reducing/ stabilizing agents. The HP $\beta C D$ was also used as fiber matrix for the electrospinning of NF composites. This is a facile and "green" route for fabricating functional NF incorporating Au-NP. This is not limited to Au-NP since HP $\beta \mathrm{CD}$ or native CD have capability to reduce and/or stabilize other kinds of metal NP such as silver, platinum and palladium, etc. Electrospinning of metallic NP incorporating NF would have exclusive properties by combining the very large surface area of NF with specific functionality of the metal NP and CD. For instance, the HP $\beta C D / A u-N P-N F$ and their nanowebs would find a wide range of biomedical applications due to their biologically compatible characteristics as well as the specific inclusion complexation ability of the CD molecules. It is also worth mentioning that HP $\beta C D$ NF are water soluble, therefore, post treatment such as crosslinking the NF is required for some of the bioapplications where aqueous medium is present.

\section{Acknowledgements}

State Planning Organization (DPT) of Turkey is acknowledged for the support of UNAM-Institute of Materials Science \& Nanotechnology. Dr T. Uyar acknowledges EU FP7-Marie Curie-IRG for funding NANOWEB (PIRG06-GA-2009-256428). A. Celebioglu acknowledges TUBITAK-BIDEB for National PhD Scholarship. The authors thank to M. Güler for the TEM/STEM imaging.

\section{Notes and references}

1 (a) M.-C. Daniel and D. Astruc, Chem. Rev., 2004, 104, 293-346; (b) R. R. Arvizo, S. Bhattacharyya, R. A. Kudgus, K. Giri, R. Bhattacharya and P. Mukherjee, Chem. Soc. Rev., 2012, 41, 2943-2970.

2 (a) S. Link, Z. L. Wang and M. A. El-Sayed, J. Phys. Chem. B, 1999, 103, 3529-3533; (b) J. Huang, L. Zhang, B. Chen, N. Ji, F. Chen, Y. Zhang and Z. Zhang, Nanoscale, 2010, 2, 2733-2738.

3 M. J. Laudenslager, J. D. Schiffman and C. L. Schauer, Biomacromolecules, 2008, 9, 2682-2685.

4 J. Cai, S. Kimura, M. Wada and S. Kuga, Biomacromolecules, 2009, 10, 87-94.
5 (a) H. Zhu, M. Du, M. Zou, C. Xu, N. Li and Y. Fu, J. Mater. Chem., 2012, 22, 9301-9307; (b) H. Wu, X. Huang, M. Gao, X. Liao and B. Shi, Green Chem., 2011, 13, 651-658.

6 (a) T. Huang, F. Meng and L. Qi, J. Phys. Chem. C, 2009, 113, 13636-13642; (b) J.-P. Sylvestre, A. V. Kabashin, E. Sacher, M. Meunier and J. H. T. Luong, J. Am. Chem. Soc., 2004, 23, 7176-7177; (c) J. Liu, J. Alvarez, W. Ong, E. Román and A. E. Kaifer, J. Am. Chem. Soc., 2001, 123, 11148-11154; (d) Y. Liu, K. B. Male, P. Bouvrette and J. H. T. Luong, Chem. Mater., 2003, 15, 4172-4180; (e) S. Pande, S. K. Ghosh, S. Praharaj, S. Panigrahi, S. Basu, S. Jana, A. Pal, T. Tsukuda and T. Pal, J. Phys. Chem. C, 2007, 111, 10806-10813; (f) C. H. Bernard, J. Yang and W. Y. Fan, J. Phys. Chem. C, 2008, 112, 4141-4145.

7 (a) J. Szejtli, J. Mater. Chem., 1997, 7, 575-587; (b) M. Messner, S. Kurkov, P. Jansook and T. Loftsson, Int. J. Pharm., 2010, 387, 199-208.

8 (a) J. Szejtli, Chem. Rev., 1998, 98, 1743-1753; (b) A. Hedges, Chem. Rev., 1998, 98, 2035-2044; (c) A. Harada, R. Kobayashi, Y. Takashima, A. Hashidzume and H. Yamaguchi, Nat. Chem., 2011, 3, 34-37; (d) J. W. Chung, Y. Guo, R. D. Priestley and S.Y. Kwak, Nanoscale, 2011, 3, 1766-1772.

9 W. Liu, A.-K. Herrmann, D. Geiger, L. Borchardt, F. Simon, S. Kaskel, N. Gaponik and A. Eychmüller, Angew. Chem., Int. Ed., 2012, 51, 5743-574.

10 J. Alvarez, J. Liu, E. Román and A. E. Kaifer, Chem. Commun., 2000, 13, 1151-1152.

11 (a) S. Ramakrishna, K. Fujihara, W. Teo, T. Lim and Z. Ma, in An Introduction to Electrospinning and Nanofibers, World Scientific Publishing Company, 2005; (b) A. Greiner and J. Wendorff, Angew. Chem., Int. Ed., 2007, 46, 5670-5703; (c) S. Ramakrishna, K. Fujihara, W. E. Teo, T. Yong, Z. Ma and R. Ramaseshan, Mater. Today, 2006, 9, 40-50; (d) J. Xie, M. R. MacEwan, A. G. Schwartz and Y. Xia, Nanoscale, 2010, 2, 35-44; (e) T. Uyar, R. Havelund, J. Hacaloglu, F. Besenbacher and P. Kingshott, ACS Nano, 2010, 4, 5121-5130; $(f)$ H. Li, W. Zhang, S. Huang and W. Pan, Nanoscale, 2012, 4, 801-806.

12 (a) T. Uyar, P. Kingshott and F. Besenbacher, Angew. Chem., Int. Ed., 2008, 47, 9108-9111; (b) J. Song, M. Chen, M. B. Olesen, C. Wang, R. Havelund, Q. Li, E. Xie, R. Yang, P. Bøggild, C. Wang, F. Besenbacher and M. Dong, Nanoscale, 2011, 3, 4966-4971; (c) A. Celebioglu and T. Uyar, Langmuir, 2011, 27, 6218-6226; (d) M. Chen, S. R. Nielsen, T. Uyar, S. Zhang, A. Zafar, M. Dong and F. Besenbacher, J. Mater. Chem. C, 2013, 1, 850-855; (e) F. Yao, L. Xu, B. Lin and G.-D. Fu, Nanoscale, 2010, 2, 1348-1357.

13 (a) C. D. Saquing, J. L. Manasco and S. A. Khan, Small, 2009, 5, 944-951; (b) L. Matlock-Colangelo and A. J. Baeumner, Lab Chip, 2012, 12, 2612-2620; (c) P. Gomathi, D. Ragupathy, J. H. Choi, J. H. Yeum, S. C. Lee, J. C. Kim, S. H. Lee and H. D. Ghim, Sens. Actuators, B, 2011, 153, 44-49; (d) S. Kundu, R. S. Gill and R. F. Saraf, J. Phys. Chem. C, 2011, 115, 15845-15852; (e) Z. Zhang, C. Shao, P. Zou, P. Zhang, M. Zhang, J. Mu, Z. Guo, X. Li, C. Wang and Y. Liu, Chem. Commun., 2011, 47, 3906-3908.

14 (a) A. Celebioglu and T. Uyar, Chem. Commun., 2010, 46, 6903-6905; (b) A. Celebioglu and T. Uyar, Nanoscale, 2012, 4, 621-631.

15 I. Pastoriza-Santos and L. M. Liz-Marzán, Adv. Funct. Mater., 2009, 19, 679-688.

16 J. Liu, G. Qin, P. Raveendran and Y. Ikushima, Chem.-Eur. J., 2006, 12, 2131-2138. 
17 (a) Y.-L. Wu and J. Li, Angew. Chem., Int. Ed., 2009, 48, 3842-3845; (b) S. Zhang, G. Leem, L. Srisombat and T. R. Lee, J. Am. Chem. Soc., 2008, 130, 113-120.

18 (a) G. Merga, N. Saucedo, L. C. Cass, J. Puthussery and D. Meisel, J. Phys. Chem. C, 2010, 114, 14811-14818; (b) Z. Shervani and Y. Yamamoto, Carbohydr. Res., 2011, 346, 651-658.

19 T. Ishizaka, A. Ishigaki, H. Kawanami, A. Suzuki and T. M. Suzuki, J. Colloid Interface Sci., 2012, 367, 135-138.
20 A. V. Kabashin, M. Meunier, C. Kingston and J. H. T. Luong, J. Phys. Chem. B, 2003, 107, 4527-4531.

21 D. Joseph and K. E. Geckeler, Langmuir, 2009, 25, 13224-13231.

22 A. Mazzaglia, L. Monsu' Scolaro, A. Mezzi, S. Kaciulis, T. De Caro, G. M. Ingo and G. Padeletti, J. Phys. Chem. C, 2009, 113, 12772-12777.

23 P. Tripathy, A. Mishra, S. Ram, H.-J. Fecht, J. Bansmann and R. J. Behm, Nanotechnology, 2009, 20, 075701. 